\title{
território, infância, palavras e a fabricação de um problema: modos de habitar
}

\author{
alessandra de barros piedras lopes ${ }^{1}$ \\ colégio pedro ii - brasil
}

resumo

Este relato de experiência pretende, mais do que qualquer outra coisa, fabricar um problema. Um problema que tem a ver com crianças e adultos e os mundos que compartilham em uma escola de Educação Infantil. E aqui já se coloca uma primeira questão: seriam mundos ou territórios? É possível que ao considerar as relações entre mundos e territórios e quem os cria, importe mais os movimentos que provocam do que propriamente o compartilhar algo? Ou antes, que não importe realmente o compartilhar algo; que o comum diga respeito a algo que não se traduz em um compartilhar? Um animal de estimação adotado após sua morte, e a morte de um animal; as diversas leituras de uma história; a definição de um conceito e o que diz uma palavra; uma leitura de uma imagem. Todos esses, acontecimentos em uma escola de Educação Infantil. Acontecimentos que se entrelaçam a outros. Encontrariam sentido em palavras como território, movimento, mundo, lugar, habitar, brincar? Como se entrelaçam, se atravessam, se esbarram, colidem? Nos movimentos que nos impelem a constituir territórios, em marcações, limites e fronteiras que nos constituem, encontramos pessoas, ideias, movimentos. Encontramos a nós mesmos? Outros? E que "mesmo" e que "outros" existem em nós? Atravessada, arrastada pela infância, busco um estilo a expressar esse encontro. Encontro com uma infância que faz surgir novos sentidos dos sentidos "mesmos" e "outros", de sentidos sempre outros, a diferir. Pode a infância encontrar modos de habitar uma palavra, habitar a linguagem? Um exercício de imaginar onde se encontram territórios, infância, linguagem; onde nos encontramos. Como nomear tal lugar: comum, singular, nós outros? Se nos constituímos em identificações que nos levam sempre a outros, a diferir, o que nos faz iguais, o que nos faz identificar nós outros?

palavras-chave: infância; território; movimento; devir; estilo.

\section{territory, childhood, words and to fabricate a problem: ways of inhabiting}

abstract

This experience record aims, more than anything else, to fabricate a problem. A problem that has to do with children and adults and the worlds they share in a school of early childhood education. Already, a question arises: would that be worlds or territories? Is it possible that when considering the relationship between worlds and territories and who creates them, it matters more the movements that made them be them the fact that they can or cannot, and how could they, be shared? That the sharing of a world or territory is not in itself as important as the movement they provoke as well as provoke them to be? That is, it does not matter the sharing of something; this thing we call "common" concerns something that does not translate into a share? An animal adopted after its death, and the death of an animal; the various readings of a story; the definition of a concept and what a word means; a reading of an image. All these, events in a school of early childhood education. Events that intertwine to others. Could they find meaning in words like territory, movement, world, place, inhabit, play? How do they entwine, traverse each

1E-mail: alessapiedras@gmail.com 
território, infância, palavras e a fabricação de um problema: modos de habitar

other, collide? Movements that urge us to establish territories in markings, borders and boundaries that constitutes them as well as ourselves, provoke encounters with people, ideas, movements. Do we find ourselves? Others? And which "selves" and which "others" are there in ourselves? Traversed by childhood, dragged by it, I seek a style to express this encounter. An encounter with childhood that gives rise to new meanings, meanings that could not be the same, that are always "others", that differ. Can childhood find ways to inhabit a word, to inhabit the language? An exercise of imagining where territories, childhood, language can encounter; where we encounter each other. How to name such a place: common, singular, we-others? If we constitute ourselves in identifications that lead us always to others, to differ, what makes us equal, what makes us identify us-others?

key-words: childhood; territory; movement; becoming; style.

\section{territorio, infancia, palabras y la fabricación de un problema: modos de habitar}

resumen

Este relato de experiencia desea, más que cualquier otra cosa, hacer un problema. Un problema que tiene que ver con los niños y los adultos y los mundos que comparten en una escuela de Educación Infantil. Y aquí ya esta una primera pregunta: serían mundos o territorios? Es posible que, al considerar la relación entre los mundos y territorios y quién los crea, importa más los movimientos que causan que lo compartir algo? O mejor dicho, que no importa el compartir algo; que el común tiene que ver más bien con algo que no se traduce en un compartir? Una mascota adoptada después de su muerte, y la muerte de un animal; las diversas lecturas de una historia; la definición de un concepto y decir una palabra; una lectura de una imagen. Todos estos, acontecimientos en una escuela de Educación Infantil. Eventos que se entrelazan con otros. Encontran sentido en palabras como territorio, movimiento, mundo, lugar, vivir, jugar? Como se entrelazan, se atravesan, si topan, si chocan? En los movimientos que nos instan a constituir territorios, en las marcacións, los límites y las fronteras que nos constituyen, encontramos personas, ideas, movimientos. Encontramos nosotros mismos? Otros? Y que "mismos" y que "otros" existen en nosotros? Atravesada, arrastrada por la infancia, busco un estilo a expresar este encuentro. Encuentro con una infancia que hace surgir nuevos sentidos de los sentidos "mismos" y "otros", de sentidos siempre otros, a diferir. ¿Puede la infancia encontrar formas de habitar en una palabra, habitar la lenguaje? Un ejercicio de imaginar dónde se encuentran territorios, infancia, lenguaje; dónde nos encontramos. Como nominar tal lugar: común, singular, nosotros? Si nos constituimos en identificaciones que nos llevan siempre a otros, a diferir, lo que nos hace iguales, lo que nos hace identificar nosotros?

palabras clave: infancia; territorio; movimiento; devenir; estilo. 
território, infância, palavras e a fabricação de um problema: modos de habitar

Por que escrevemos? Por ter algo a dizer ou justamente por não ter? Pareceme que poderíamos escrever os mais diversos textos pelas mais diversas razões. $\mathrm{O}$ movimento que leva uma pessoa a escrever poderia surgir de um desejo, uma vontade de comunicar algo, dizer algo a alguém, ou por não ter algo a dizer, e, assim, começar a escrever esse "não algo".

Um possível ímpeto inicial para uma escrita como esta - um texto acadêmico-científico, filosófico - estaria no surgimento de uma questão. Uma questão surge, e ao surgir provoca um movimento. Começamos a caminhar na questão, investigamos a questão em foco, e marcamos nosso caminhar com palavras que se organizam em um texto a ser compartilhado, oferecido a um outro, a outros.

Poderíamos, por outro lado, considerar que o movimento da escrita não é resultado do surgimento de uma questão. Poderíamos nos pôr a escrever justamente para fazer surgir uma questão. A escrita faria parte, aqui, da fabricação de uma questão. Uma invenção para a qual muitos e diversos elementos concorrem. Algo de espontâneo e planejado, de surpreendente e esperado coalesce, assume forma em palavras. Palavras a conversar, a conviver, que algo ou nada dizem.

Ao falar sobre o que é e para que serve uma conversa, Deleuze (1998, p.2), em um diálogo com Claire Parnet, assim começa

É difícil "se explicar" - uma entrevista, um diálogo, uma conversa. A maior parte do tempo, quando me colocam uma questão, mesmo que ela me interesse, percebo que não tenho estritamente nada a dizer. As questões são fabricadas, como outra coisa qualquer. Se não deixam que você fabrique suas questões, com elementos vindos de toda parte, de qualquer lugar, se as colocam a você, não tem muito o que dizer. A arte de construir um problema é muito importante: inventa-se um problema, uma posição de problema, antes de se encontrar a solução.

Escrevo este texto em busca de algo a dizer, na fabricação de um problema. Não há, ainda, um problema, não há uma questão. Há elementos, como aponta Deleuze. Conversas, experiências, acontecimentos em uma escola de Educação Infantil. Há ideias e conceitos: brincar, território, infância, movimento, devir, lugar, 
território, infância, palavras e a fabricação de um problema: modos de habitar

habitar. O que as experiências vivenciadas podem falar dessas ideias e conceitos e vice-versa? De que forma esses atravessamentos podem fazer criar um problema? Poderiam de fato? São os problemas que nos põem em movimento? E por que isso importa?

"É isso que faz um mundo", afirma Deleuze (1996) ao discorrer sobre o animal em seu Abecedário. Em "um mundo formigante", diz ele, o animal - um carrapato, neste caso - reage a três coisas: luz, cheiro, e uma sensação tátil. Estas três coisas fazem o mundo do animal, que pode, enquanto não reage a estas três coisas, enquanto não se põe em movimento, levar, por anos, uma existência amorfa, uma existência indiferente, apática.

Movimentar é necessário à criação de um mundo, poderíamos pensar. Criar um mundo, necessário à vida para além e aquém de uma existência amorfa. Criamos mundos juntos, como espécie, por contágio? Reagimos, como espécie, aos mesmos estímulos? Habitamos, assim, um mesmo mundo?

Deleuze (1996) afirma, por um lado, que "muita gente, muitos humanos não têm mundo", que "vivem a vida de todo mundo, ou seja, de qualquer um, de qualquer coisa". Uma existência amorfa? Há algo singular na identificação dos estímulos que noz fazem movimentar, para aquém ou além do que nos identifica como espécie, por contágio ou não.

À afirmação de que "os animais têm mundo", Deleuze (1996) agrega a ideia de que "não basta ter um mundo para ser um animal". Importante, também, é a constituição de um território:

[...] os animais de território são prodigiosos, porque constituir um território, para mim, é quase o nascimento da arte. [...]As histórias de glândulas anais, de urina, com as quais eles marcam as fronteiras de seu território. O que intervém na marcação é, também, uma série de posturas, por exemplo, se abaixar, se levantar. Uma série de cores, os macacos, por exemplo, as cores das nádegas dos macacos, que eles manifestam na fronteira do território... Cor, canto, postura, são as três determinações da arte, quero dizer, a cor, as linhas, as posturas animais são, às vezes, verdadeiras linhas. Cor, linha, canto. É a arte em estado puro. E, então, eu me digo, quando eles saem de seu território ou quando voltam para ele, seu comportamento... O território é o domínio do ter. É curioso que seja no ter, isto é, minhas propriedades, minhas propriedades à maneira de Beckett ou de Michaux. O território são as propriedades do animal, e sair do território é se aventurar. Há bichos que reconhecem seu cônjuge, o reconhecem no território, mas não fora dele. (DELEUZE, 1996). 
Movimentar é preciso para constituir um território. O deslocamento é realizado no constituir, no marcar e mapear um território. Um território propriedade de quem o constitui, que nesse constituir cria o que constitui a si ao mesmo tempo que o "seu"; que constitui a si no que é "seu", no que traz a marca do que é familiar, do que é confortante, do que é reconhecível. Um ser que não se desfaz no ter, e vice-versa. Como propõe Zourabichvili (2004, p.23 e 24),

\begin{abstract}
marca constituinte de um domínio, de uma permanência', não de um sujeito, o território designa as relações de propriedade ou de apropriação, e concomitantemente de distância, em que consiste toda identificação subjetiva - 'um ter mais profundo que o ser.
\end{abstract}

Há um deslocamento que força os limites e fronteiras de um território, até que algo faça migrar em um movimento de desterritorialização (DELEUZE; GUATTARI, 2012), desfazendo-o sem que isso dele nos separe, refazendo-o aqui, lá e ali. Não parece possível que em movimentos de territorialização, desterritorialização e reterritorialização (DELEUZE; GUATTARI, 2012) um território permaneça, que possamos permanecer. O que formiga em nós e nos leva a pisar para além das fronteiras de nosso território? O que nos impele ao caos?

\title{
animal domesticado, bicho de estimação
}

Um dia qualquer, uma menina de quatro anos, aluna do Colégio Pedro II, resolveu que faria de um belo inseto que cruzou seu caminho seu bichinho de estimação. Era um belo inseto realmente. O corpo de um vermelho brilhante, as asas transparentes com um brilho esverdeado. A menina ficou maravilhada, bem como as outras crianças de sua turma. Em meio ao seu maravilhamento, um colega, pisou no inseto. Ele não gostava de insetos, principalmente, disse ele, invadindo sua escola, seu território. Todas as crianças ficaram revoltadas e entristecidas. Conversei com o colega, tentando, através de analogias, dimensionar seu ato. Questionei como poderia ter matado o animal, que o mesmo poderia ser a mãe de alguém e que seus filhos e suas filhas não teriam mais ninguém. Ele respondeu: "tem o pai deles". A menina, então, se aproximou com o inseto em suas mãos, e com um sorriso no rosto afirmou que iria levá-lo para casa, seria seu bichinho de estimação. Após alguns segundos de silêncio e contemplação, perguntei se ela entendia que o animal estava morto. Ela disse que sim, e mais uma vez afirmou que levaria a "borboleta" para casa e cuidaria bem dela. Comentei que ela poderia conversar com sua mãe e seu pai para prender 
território, infância, palavras e a fabricação de um problema: modos de habitar

a "borboleta" com um alfinete, começar uma coleção de insetos. Horrorizada, a menina rejeitou a ideia veementemente: "isso vai machucar minha borboleta".

Faria sentido questionar a natureza da morte e a possibilidade de sentir dor? A relação de encantamento que a menina começara a criar com o inseto não se interrompeu com sua morte. Cuidaria de sua "borboleta" na mesma medida que cuidava de seu encantamento por ela, faria disso tudo algo seu. Sua relação com o animal e com aquele momento não passava por qualquer desejo de constituir uma coleção de insetos mortos.

A opção por fazer de um bicho morto seu animal de estimação poderia causar estranhamento, levantar questionamentos, fazer pensar. Um estranhamento que contagia outras razões para a escolha de um bicho de estimação após uma breve e superficial busca na internet. Nesta, surgem ideias como: "Além de bonitinhos e divertidos, os animais ajudam a desenvolver o senso de responsabilidade, a autoestima e a educação sentimental da garotada" 2, "Cão, gato, peixe, pássaro... qual o animal de estimação ideal para você?"3, "Seis provas de que ter bichos de estimação faz bem à saúde" 4 . De forma geral, apresentam uma relação utilitária, com funções definidas a justificar a aquisição de um bicho de estimação. Uma relação que, em determinado site, parece tornar nebulosas as fronteiras entre seres animados e inanimados:

\section{Animais de estimação [...] uma responsabilidade para a vida toda, por isso você deve ter a responsabilidade de escolher bem com quem vai dividir a sua vida. Eles são animais vivos - não bichos de pelúcia que podem ser "jogados fora" quando você se cansar deles 5 .}

Seres e objetos inanimados podem, então, ser jogados fora quando nos cansamos deles? E se podem, o que impede que façamos o mesmo com seres vivos que nos "cansem"? Se as relações que estabelecemos com as coisas e seres que encontramos são as mesmas, não fazemos dessas coisas e seres os mesmos?

Han Bing, um artista chinês, realiza desde o ano 2000 uma série de

\footnotetext{
${ }^{2}$ http:/ / www.pediatriaemfoco.com.br/posts.php?cod=161\&cat $=4$

${ }^{3}$ http://www.petbrazil.com.br/bicho/bichoid.htm

${ }^{4}$ http://veja.abril.com.br/noticia/saude/seis-provas-de-que-ter-um-bicho-de-estimacao-faz-bema-saude

${ }^{5} \mathrm{http} / / /$ pt.wikihow.com/Escolher-um-Bicho-de-Estima\%C3\%A7\%C3\%A3o
} 
intervenção social, a qual denomina Andando com o Repolho ${ }^{6}$. São trabalhos performáticos de vídeo e foto. $\mathrm{O}$ artista anda com um repolho em uma coleira em locais públicos ao redor do mundo. Andando com o Repolho, podemos conferir na página virtual do artista, se propõe a ser "uma divertida torção em um assunto sério - a maneira como nossas práticas cotidianas constituem 'normalidade' e como nossas identidades são geralmente constituídas pelo ato de reivindicar objetos como possessões" 7 (tradução minha).

Seria a possessão de objetos, animados ou inanimados, aquilo que nos constitui? Seriam as práticas, ações, gestos no espaço, no cotidiano e a normalidade, ou anormalidade, que criam aquilo que nos constitui? Assumimos forma a partir da apropriação de objetos, referências que identificamos e escolhemos, gestos e posturas, marcas constituintes de um território que é constituído ao mesmo tempo que nos constituiu. Seria possível imaginar que nos constituímos em um território ao passo que constituímos um território a tal ponto que seja difícil entender os limites de um e outro? Podemos nos constituir como território?

Constituímos territórios em uma mistura entre o espaço que ocupamos, nós mesmos, nossas movimentações e as marcações que criamos para demarcar limites e fronteiras. Era isso que acontecia quando o colega matou o inseto que invadia sua escola; ele, que dizia não "gostar" de insetos? É isso que faz a menina ao adotar, tornar "seu", um inseto belo e morto como bicho de estimação? Cuida do inseto, de si e do encantamento que encontrou. Cuidamos das relações e dos sentidos que criamos.

Na mesma escola já mencionada, encontramos um gafanhoto morto em cima de nossa plantação de melancias. As crianças criaram as mais fantásticas hipóteses de como ele fora parar ali. Preocupado com o que iria acontecer com o gafanhoto, um colega propôs: “Eu posso levar o grilo... pro lar dele. Eu tenho um grilo igual esse. A minha mãe e o meu pai

\footnotetext{
${ }^{6}$ Walking the Cabbage 遛白菜漫游记, tradução livre.

${ }^{7}$ Walking the Cabbage is a playful twist on a serious subject - the way our everyday practices serve to constitute "normalcy" and our identities are often constituted by the act of claiming objects as our possessions. (http://www.hanbingart.com/index.php?/artworks/-the-walking-the-cabbageproject--/)
} 
território, infância, palavras e a fabricação de um problema: modos de habitar

podem pegar outro grilo na caverna do grilo... Aí, o pai do grilo vai levar ele pra casa dos grilos pra ele ficar bem, bem feliz". Após algumas sugestões, decidimos enterrá-lo no pátio, perto de uma grande árvore. As crianças compartilhavam a preocupação de seu colega com a solidão do gafanhoto, que seria enterrado sozinho ao pé da árvore. Dois meninos que passavam enquanto seguíamos o cortejo do gafanhoto, após se inteirarem da situação, disseram que haviam visto um outro gafanhoto perto de um dos bebedouros. Comentei sobre a coincidência da existência de um outro gafanhoto morto, que poderia fazer companhia ao que haviamos encontrado, e os meninos responderam: "Ele não tá morto, mas a gente mata ele, e aí enterra ele junto com o outro".

Soluções simples para questões complexas? Soluções complexas para questões simples? O que faz diferir morte e vida? O que nos faz diferir uns dos outros e o que nos faz iguais? A ideia de que ao nos constituirmos constituímos uma identidade parece tão contraditória quanto a própria ideia que traz a palavra identidade. Como significante, encontramos significados que falam de algo que apresenta ao mesmo tempo "igualdade que se verifica para todos os valores da incógnita"8 e "conjunto dos caracteres próprios de uma pessoa, [...], o qual é considerado exclusivo dela e, consequentemente, considerado, quando ela precisa ser reconhecida" ${ }^{\prime}$. Uma questão meramente combinatória? O que nos faz únicos e ao mesmo tempo comuns? O que faz de nós outros? Poderíamos esperar consistência, coerência e constância de cada combinação?

Deleuze (1996) fala em marcações de fronteiras: cor, canto e postura; cor, linha e canto. Zourabichvili (2004, p.24), ao falar de Deleuze, explicita que "o território designa as relações de propriedade ou de apropriação, e concomitantemente de distância, em que consiste toda identificação subjetiva". Não identidade, mas "identificação subjetiva". É interessante a distinção. "Identidade" é um termo que vem do latim escolástico identitate: idem + entitas, mesmo/mesma + ser; "identificar" é um termo que deriva também do latim escolástico: identicu + fic/facere + ar, perfeitamente igual + fazer + desinência modotemporal (NASCENTES, 1955; SILVA, 2014). Somos, e não somos, somente para ser

${ }^{8}$ Disponível em: <http:/ / michaelis.uol.com.br/busca?id=vkAAV>

9 ibid 
de novo? Não somos sendo e somos não sendo? Uma questão modo-temporal: ser e fazer ser?

O que faz de um território um lugar e não simplesmente um espaço? Se um lugar é feito no espaço - assume formas, limites, fronteiras, marcos naquilo que é feito dele -, é de um espaço somente até o ponto que não mais dele é, até que não mais preso a ele está? As diferenças entre lugar e espaço parecem estar naquilo que faz de um espaço - ou do espaço - algo indefinido, impessoal, e do lugar algo que é feito nosso, constituído pelas marcas daqueles que o habitam juntos. É um espaço ou um lugar que habitamos? É o ovo ou a galinha, ou antes, poderíamos nos perguntar, é o ovo ou o milho?

Em uma oficina que explorava os limites entre ficção e realidade em um congresso em Buenos Aires, Argentina, me vi imersa em questões que conjugavam espaço e lugar. Foi proposto que todos escrevessem algumas linhas para um "lugar", físico ou não, existente ou não. Escrevi: “Um mar nos separa; um céu também... provavelmente muitas coisas. Tanto nos separa! Mas algo certamente nos aproxima. Um cheirinho de alecrim, como sugere Chico Buarque? Pé no chão e sombras de árvores, sorrisos e dramas, uma vida, um mundo". Ouvi algumas linhas escritas por outros, compartilhei com todos as minhas, e me capturou - em português e, especialmente, em espanhol - a concretude das palavras que iam se juntando umas às outras. Envolta pelas primeiras palavras que bailavam juntas, me vi transportada para o alto de uma montanha, sentindo o silêncio e o frio que a habitavam. Logo depois, perdida em incompreensibilidades, ouvia sobre paredes brancas sem entender por que; "via" olhos azuis e verdes assumirem forma sem saber exatamente a relação que criavam e os criava; ouvia sobre distâncias e infâncias, ao mesmo tempo que era invadida pelas distâncias que a língua cria, que línguas distintas criam. Voltei às minhas próprias palavras, e as entendi diferentes. Não mais pareciam falar sobre uma ilha na Baía de Angra dos Reis, no Rio de Janeiro, mas sim sobre aquele momento que vivia ali, exatamente naquele instante, naquele lugar. Habitamos lugares? E o que faz um lugar? Naquele instante, habitava as palavras que havia colocado lado a lado, marcações de um lugar para fora delas e que passaram a constituir um lugar próprio, um território.

Podemos pensar palavras como lugares habitáveis? A partir da experiência na oficina relatada, senti e pensei as palavras como rarefeitas. $O$ ar rarefeito 
território, infância, palavras e a fabricação de um problema: modos de habitar

dificulta a respiração; com menos oxigênio, é preciso um esforço maior para conseguir o necessário. Poderiam ser as palavras rarefeitas, como o ar? Estariam cheias ou vazias de quê? Sons, letras, cheiros, texturas, imagens... O que podem ter de mais ou de menos? E talvez "rarefeitas" possa fazer sentido, se imaginarmos que ao se fazerem rarefeitas, abrem espaço, se fazem esburacadas, permeáveis...

Palavras como lugares habitáveis? Nós como lugares habitáveis às palavras? Consideremos que um território vale, como nos diz Deleuze (1996), o movimento de sair dele: desterritorializar; linhas de fuga que nos arrastam, que desfazem um território que não pode existir sem pertencer a alguém, a algo que o constituiu. E assim como movimentos marcam um território - territorializam e reterritorializam -, movimentos desterritorializam, em linhas de fuga que nos fazem devir:

Devir é jamais imitar, nem fazer como, nem ajustar-se a um modelo, seja ele de justiça ou de verdade. Não há um termo de onde se parte, nem um ao qual se chega ou se deve chegar. Tampouco dois termos que se trocam. A questão "o que você está se tornando?" é particularmente estúpida. Pois à medida que alguém se torna, o que ele se torna muda tanto quanto ele próprio. [...] Os devires não são fenômenos de imitação, nem de assimilação, mas de dupla captura, de evolução não paralela, núpcias entre dois reinos. (DELEUZE; PARNET, 1998, p.3)

O devir nos fala não de um processo que oscila entre a subjetivação e a dessubjetivação, voltando à subjetivação, mas de um movimento que nos arrasta em linhas de fugas; que é só movimento. Uma desterritorialização que é sempre desterritorialização, que se reterritorializa na própria desterritorialização. Não se trata de ir de um polo a outro, ser ou não ser. Como poderíamos ser sem não ser, não ser sem ser?

Existimos envoltos por linguagem, existimos no corpo de palavras tanto como em nossos próprios corpos. Limites, contudo, não tão precisos ou objetivos como poderíamos pensar. Palavras deslocam, se deslocam; escorregam e escorrem, escapam e nos acham. São permeáveis, deixam passar o ar, confundem-se com ele, deixam passar tantas coisas mais, se desfazem e refazem. Também nossos corpos se desfazem em devires, se misturam, se fazem outros, são feitos outros em encontros. Como poderiam ser ou não ser? Como poderíamos? 


\section{"a palavra, esta corriqueira"}

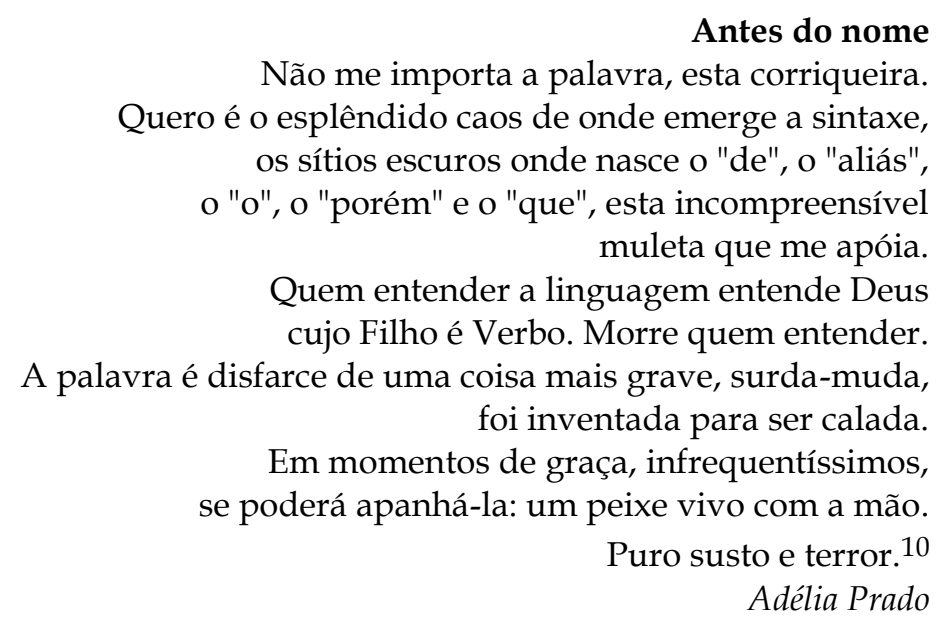

Constituímos nossa existência envoltos em linguagem, e nela, entre muitas e outras possibilidades, em palavras. Podemos habitar palavras como habitamos territórios, constituindo-as e nos constituindo em movimentos de apropriação e demarcação que territorializam e constituem a nós mesmos? Sujeitos a uma desterritorialização absoluta? A uma mudança que não é simplesmente mudança, mas mudar, em um infinitivo que sempre é, sempre diferindo?

[...] Os devires são o mais imperceptível, são atos que só podem estar contidos em uma vida e expressos em um estilo. Os estilos, e tampouco os modos de vida, não são construções. No estilo não são as palavras que contam, nem as frases, nem os ritmos e as figuras. Na vida não são as histórias, nem os princípios ou as consequências. Sempre se pode substituir uma palavra por outra. Se esta não lhe agrada, não lhe convém, pegue outra, coloque outra no lugar. Se cada um fizer esse esforço, todo mundo poderá se compreender, e não haverá mais razão de colocar questões ou fazer objeções. Não há palavras próprias, tampouco metáforas (todas as metáforas são palavras sujas, ou as criam). Há apenas palavras inexatas para designar alguma coisa exatamente. Criemos palavras extraordinárias, com a condição de usá-las da maneira mais ordinária, e de fazer existir a entidade que elas designam do mesmo modo que o objeto mais comum. (DELEUZE; PARNET, 1998, p. 3 e 4).

Talvez as crianças façam isso da forma mais interessante: usar palavras inexatas para designar algo exatamente. Exercitar uma mudança que é mudar ao mesmo tempo que mudança. Acontecimento em um tempo que é e não é, tempo e não tempo, um antes e depois que é também um entretempo, a atravessar, romper, provocar um corte no tempo que se faz antes e depois. Aión, um tempo indefinido,

\footnotetext{
${ }^{10}$ Disponível em: <http:// lectusexlibris.blogspot.com.br/2009/10/antes-do-nome-adeliaprado.html>
} 
território, infância, palavras e a fabricação de um problema: modos de habitar

que acontece em um instante, em uma eternidade que não se faz geral mas singular; Chronos, um tempo que se faz na generalidade de um antes e de um depois, nunca presente. Pensar com Heráclito em seu fragmento 52: “O tempo é uma criança que brinca; o reino de uma criança" (KOHAN; VIGNA, 2013, p.17), poderia nos levar a cutucar as marcas desse domínio. Não marcas de permanência, mas intensidades que nos desterritorializam, que fazem surgir novos sentidos, nas relações que esses criam com as palavras que os sugerem, que os inventam.

O dia era 20 de março de 2015, e acabáramos de ler "A verdadeira história dos três porquinhos". Descobrimos que o lobo acabou essa história preso, na cadeia. A história trazia a versão do lobo do clássico conto sobre os três porquinhos. Nela, ele defendia que simplesmente havia batido às portas de seus vizinhos, os porquinhos, pedindo uma xícara de açúcar para fazer um bolo para sua vozinha. Doente, tomado por espirros fortíssimos, fez voar - sem querer - pelos ares as casas dos porquinhos, e eles caíram mortos, presuntinhos a serem consumidos; como não comê-los, se perguntava o lobo. Após a história, conversamos sobre o porquê da prisão do lobo. Logo foi dito: "Porque ele pegou o açúcar da vovozinha". Arriscaram: "Acho que eu sei! Acho que ele pegou os 3 porquinhos e comeu, e depois foi preso". Uma das crianças compartilhou o que pensava daquele lobo: "Lobo mau, chuva já daí! Ele é feio. Lobo mau é feio! Ele roubou o açúcar da vovozinha. Ele tá no castigo". Outra criança acreditou ser necessário esclarecer a questão: "Eu acho que o lobo não tá de castigo porque ele... ele pegou o açúcar do porquinho e levou lá pra fora. Aí, ele jogou o açúcar e ele espirrou, e ficou muito mau, aí, ele foi pra cadeira". Outra, ainda, complementou: "Ele ficou muito preso... ele... e a polícia prendeu ele, e chegou lá na cadeia de limão, e ficou muito triste".

A apropriação das crianças - de 3 anos - da história é incrível. Não só nos diferentes sentidos que criam a partir das imagens, gestos, tons e timbres de vozes durante a contação, mas nas palavras que moldam para fazê-lo. Na forma como se apropriam das palavras, como as conjugam, como as fazem suas para expressar o que querem. Ora, por que o lobo iria para a cadeia por comer porquinhos, não é isso que um lobo faz? Contudo, roubar o açúcar de uma vovozinha? Imperdoável! A expressão “chuva já daí!” expressaria uma dificuldade de enunciação da criança ou um problema de audição da professora? Independente, não nos ofereceria uma 
possibilidade de encontro com uma palavra inexata para expressar algo tão exatamente: cair, escorrer e correr com o vento. Imagine a possibilidade de chover por aí? E o que poderíamos pensar de "ir pra cadeira" e de uma "cadeia de limão"?

Palavras moldadas, moldáveis, permeáveis; desterritorializadas? Abstratas, sem forma; que forma podem assumir? Não adquirem sentido nas metáforas que poderíamos eventualmente conceber, mas na ruptura com o sentido imediato que pareciam oferecer. Uma palavra tão importante quanto desimportante é?

Em uma outra ocasião, na mesma turma, na mesma escola onde tudo isso aconteceu, conversávamos sobre luas e estrelas olhando um quadro de Candido Portinari, "Céu com estrelas". Tudo começou quando as crianças chegaram na escola compartilhando uma excitante descoberta: "a lua segue a gente!". E não só tinha manias persecutórias essa danada, que dava as caras de noite e de dia, vivia a mudar: "cheia, crescente, minguante, sorriso, banana...", nos diziam as crianças. Começamos a falar sobre o quadro de Portinari, e uma delas falou: "Tem estrela cadente". Perguntei porque pensava que era uma estrela cadente, e nos disse: "Porque ela faz um desejo que as pessoas querem". Mas qual estrela seria cadente, questionei, o que havia nela, na pintura, a dizer que era cadente. Outra criança reafirmou: "Porque ela faz um desejo. É uma estrela cadente porque é uma estrela cadente. Essa é estrela cadente, essa é estrela cadente. As duas estrelas cadentes". Entre as que foram apontadas como cadentes e aquelas que não, perguntei sobre o que as fazia diferir, e uma criança, então, disse: "É uma estrela não-cadente. Eu conheço uma estrela cadente. Ela pousa na lua, e, aí, ela vira uma estrela que não é uma estrela cadente"; a outra criança reforçou: "A estrela cadente é uma estrela muito poderosa, que faz um montão de desejo, que você acha necessário, então, ela faz...ISSO. E é por isso que se chama estrela cadente".

Onde existe a palavra, fora ou dentro dela mesma? Minha insistência em questionar a estrela cadente buscava uma identificação entre a palavra e a representação do pintor, mas isso não foi apontado por nenhuma das crianças. As relações às quais eu me prendia ao considerar uma palavra e uma imagem que apresentavam uma "estrela cadente" não encontrou ressonância nas crianças. O que há dentro de uma palavra e que relações se traçam entre o que há dentro e o que há fora?

"Eu conheço uma estrela cadente", uma afirmação potente seguida de uma 
território, infância, palavras e a fabricação de um problema: modos de habitar

relação aparentemente simples entre seu nome e o que é: uma estrela cadente só é enquanto cai, quando para de cair ela não é, é um não cair, uma estrela não cadente. Outra criança, contudo, nos diz que uma estrela "é uma estrela cadente porque é uma estrela cadente", o que importa é o poder que tem de realizar "um montão de desejo, que você acha necessário, então ela faz... ISSO". Um isso que é importante não só na enunciação do que faz mas no fazer.

Como entrar nas palavras? Podemos habitá-las? Habitar algo que é constituído em desterritorializações, em linhas de fuga que se atravessam; sentidos esquivos, escorregadios, sempre o que são e o que não são, sempre outros. Uma linguagem tão comum quanto incomum naquilo que pode nos surpreender, que pode diferir, que difere, que é não sendo e vice-versa, e nos joga em um entre, um entremeio. Podemos habitá-la?

Encontram-se pessoas (e às vezes sem as conhecer nem jamais tê-las visto), mas também movimentos, ideias, acontecimentos, entidades. Todas essas coisas têm nomes próprios, mas o nome próprio não designa de modo algum uma pessoa ou um sujeito. Ele designa um efeito, um ziguezague, algo que passa ou que se passa entre dois como sob uma diferença de potencial: "efeito Compton", "efeito Kelvin". Dizíamos a mesma coisa para os devires: não é um termo que se torna outro, mas cada um encontra o outro, um único devir que não é comum aos dois, já que eles [15] não têm nada a ver um com o outro, mas que está entre os dois, que tem sua própria direção, um bloco de devir, uma evolução aparalela. É isso a dupla captura, a vespa E a orquídea: sequer algo que estaria em um, ou alguma coisa que estaria no outro, ainda que houvesse uma troca, uma mistura, mas alguma coisa que está entre os dois, fora dos dois, e que corre em outra direção. Encontrar é achar, é capturar, é roubar, mas não há método para achar, nada além de uma longa preparação. Roubar é o contrário de plagiar, de copiar, de imitar ou de fazer como (DELEUZE; PARNET, 1998, p.6).

Podemos habitar esse entre, esse meio que é mais caos que cosmos, que é caos? Não “a palavra, esta corriqueira”, como nos diz Adélia Prado (1991, p.22), mas "o esplêndido caos de onde emerge a sintaxe, os sítios escuros onde nasce o 'de', o 'aliás', o 'o', o 'porém' e o 'que'".

E o problema?

\section{o problema}

Começaria a demarcá-lo pela pergunta que abre o texto: por que escrevemos? Esse talvez não seja O problema, mas, de fato, os problemas parecem 
ser muitos. É preciso começar a demarcá-los em algum lugar, de alguma forma. A escrita seria uma de suas marcas, a escrita de um "algo-não-algo"; um estilo que possa expressar um modo de habitar um entremeio. Uma escrita que só poderia ser expressa em um estilo. Não como construção, mas um constituir-se em ranhuras e veios - superficiais e profundos - que causem estranhamentos, maravilhamentos, encantamentos, quedas em buracos, rolamentos, gritos e sussurros. Escrevemos com(o) um estilo para fazer surgir o novo. Escrevemos para criar; criamos para escrever. Escrevemos para ser lidos?

A escrita é um encontro com o outro? Algo que acontece entre tessituras, emaranhados e nós? Nós e quem? Há algo em nós que não fale de uma mistura que se entremeia sem fim ou começo? Onde nos separamos em um algo aqui e outro ali? Onde nos entendemos em nós, em emaranhados, em atos e desatos?

Distâncias e aproximações, marcações, limites e fronteiras, movimento, territorialização e desterritorialização. O caos não é só caos, poderíamos pensar com Deleuze. Caos e cosmos em uma dança eterna; não ora um ora outro, mas juntos. Não seria interessante que pudéssemos suportar um pouco mais de caos do que nossos anseios territorialistas nos fazem delimitar? Assim como a infância pode nos apresentar por um lado uma ordem a se estruturar e a estruturar um tempo que se sucede, ela pode atravessar essa ordem, e nos apresentar o caos que permite encontros em um instante, efeitos, zigue-zagues; que faz surgir o novo. Pode a infância encontrar modos de habitar uma palavra, habitar a linguagem?

Poderíamos, talvez, imaginar um lugar onde territórios, infância, linguagem se encontram; onde nos encontramos. Como nomear tal lugar: comum, singular, nós outros? Se nos constituímos em identificações que nos levam sempre a outros, a diferir, o que nos faz iguais, o que nos faz identificar nós outros?

Seria possível pensar, aprender, encontrar, decifrar isso em uma escola de educação infantil? E o que dirá de modos de habitar uma escola de educação infantil "contidos em uma vida e expressos em um estilo" (DELEUZE; PARNET, 1998, p.3)? 
território, infância, palavras e a fabricação de um problema: modos de habitar

\section{referências}

DELEUZE, Gilles; PARNET, Claire. L'abécédaire de Gilles Deleuze. Direção de Pierre-André Boutang. Paris: Montparnasse, 1996. DVD (450 min).

DELEUZE, Gilles; PARNET, Claire. Diálogos. São Paulo: Editora Escuta, 1998.

DELEUZE, Gilles; GUATTARI, Félix. Mil platôs: capitalismo e esquizofrenia 2, vol.4. Trad. Suely Rolnik. São Paulo: Editora 34, 2012.

KOHAN, Walter Omar; VIGNA Elvira. Pensar com Heráclito. Rio de Janeiro: Lamparina, 2013.

NASCENTES, Antenor. Dicionário Etimológico da Língua Portuguesa. Rio de Janeiro: 1955.

Disponível em:

$<$ https://ia801700.us.archive.org/25/items/AntenorNascentesDicionaroEtimologicoDaLi nguaPortuguesaTomol/DicionarioEtimolgicoDaLinguaPortuguesa.pdf $>$. Acesso em: fevereiro de 2016.

PRADO, Adélia. Poesia Reunida. São Paulo: Siciliano 1991

SILVA, Deonísio da. De onde vêm as palavras: frases e curiosidades da língua portuguesa.

Editora Lexikon, 2014, 17 $7^{\mathrm{a}}$ edição.

ZOURABICHVILI, François. O Vocabulário de Deleuze. Trad. André Telles. Rio de Janeiro: Relume Dumara, 2004.

recebido em: 17.11.2017

aceito em: 28.02.2017 